2019-04-05

User-defined challenges and desiderata for robotics and autonomous systems in health and social care settings

Aguiar Noury, G

http://hdl.handle.net/10026.1/13779

10.1080/01691864.2019.1599728

Advanced Robotics

Taylor \& Francis

All content in PEARL is protected by copyright law. Author manuscripts are made available in accordance with publisher policies. Please cite only the published version using the details provided on the item record or document. In the absence of an open licence (e.g. Creative Commons), permissions for further reuse of content should be sought from the publisher or author. 


\section{User-defined challenges and desiderata for robotics and autonomous systems in health and social care settings}

Gabriel Aguiar Noury ${ }^{a^{*}}$, Hannah Bradwell ${ }^{\mathrm{b}}$, Serge Thill ${ }^{\mathrm{c}}$, Ray Jones $^{\mathrm{d}}$

agabriel.aguiar@plymouth.ac.uk, University of Plymouth, Plymouth PL4 8AA, UK; ORCID ID: 0000-0002-8553-644X

${ }^{b}$ hannah.bradwell@plymouth.ac.uk, University of Plymouth, Plymouth PL4 8AA, UK; ORCID ID: 0000-0002-9103-1069

c S.Thill@donders.ru.nl, Donders Institutefor Brain, Cognition, and Behaviour, 6525 HR Nijmegen, Netherlands; ORCID ID: 0000-0003-1177-4119

c ray.jones@plymouth.ac.uk, University of Plymouth, Plymouth PL4 8AA, UK; ORCID ID: 0000-0002-2963-3421

* corresponding author: School of Computing Electronics and Mathematics, University of Plymouth, Drake Circus, Plymouth, Devon PL4 8AA, UK 
Notes on contributors

Gabriel Aguiar Noury is a Post-Doctoral Research Fellow in Human Robot Interaction at University of Plymouth. Currently working in the eHealth Productivity and Innovation in Cornwall and the Isles of Scilly (EPIC) project as the robotics lead researcher, and in the AGE Independently project, his research revolves around innovation ecosystems and assistive robotics.

Hannah Bradwell received her Bachelor degree in Human Behavioural Studies (Hons.) from the University of Plymouth, the United Kingdom. She then obtained her MSc in Psychology from Manchester Metropolitan University, the United Kingdom. Currently, she is pursuing a Ph.D. in Applied Health at University of Plymouth since 2017. Her current research revolves around therapeutic robots.

Serge Thill is an associate professor in artificial intelligence at the Donders Institute for Brain, Cognition, and Behaviour at Radboud University in Nijmegen, the Netherlands. He received his $\mathrm{PhD}$ from the University of Leicester, UK, in 2008, after which he joined the University of Skövde, Sweden, and then the University of Plymouth, UK, before taking up his current position. His main research interests are in natural intelligence and human interaction with artificial agents (including robots and intelligent vehicles).

Ray Jones has been Professor of health informatics at Plymouth University since 2002, previously being Senior Lecturer in Public Health at Glasgow University. He leads a programme of research focussed mainly on the implementation and evaluation of eHealth including care robotics. In particular, he leads a $£ 2.7 \mathrm{~m} 3$-year project called eHealth Productivity and Innovation in Cornwall and the Isles of Scilly. Other current projects include companion robots for older people and use video calls and smart speakers in care homes. 
Word count: 4460

\title{
User-defined challenges and desiderata for robotics and autonomous systems in health and social care settings
}

\author{
Abstract. We report the needs and challenges identified by \\ health and social care professionals and service users for \\ robotics and autonomous systems that are of importance to \\ researchers and policymakers. To this end, we held eight \\ workshops in different locations across Cornwall (UK) in \\ which we raised awareness of the applications and \\ opportunities of assistive robots. The 223 participants could \\ interact physically with four robots, watched a multimedia \\ presentation including video and use-case scenarios and then \\ took part in 33 focus groups. Content analysis was carried out \\ based on summaries written by facilitators during the focus \\ groups. The focus groups produced 163 challenges that may \\ have digital solutions including 78 suitable for robotic assistive \\ technology, in three main areas: maintaining independence at \\ home, social isolation, and rurality. Although further research \\ is needed with technology and its implementation, this study \\ shows that health and social care professionals, patients, carers, \\ and students are willing to consider using robotics and \\ autonomous systems in health and social care settings.
}

Keywords: health and social care, evaluation of needs, robotics, assistive technology. 


\section{Introduction}

Robots as assistive technologies form an emerging market with increasing impact [1]. From supporting patients' cognitive abilities, to providing remote monitoring of their health status and support in activities of daily living, assistive robots have the potential to change the way we perceive and treat a range of impairments and conditions [2]. That said, to bring robotics and autonomous systems (RAS) into health and social care, research needs to be grounded in an understanding of user needs [2].

Despite ongoing research, the need for a stronger understanding in the European context has been made evident in the plans and roadmaps of several organizations. For example, the Robotics 2020 Multi-Annual Roadmap by SPARC (the Public-Private Partnership between the European Commission, and European industry and academia) highlighted the importance of exploring user needs and requirements for each RAS market domain [3]. Further, the European Civil Law Rules in Robotics study by the Directorate General for Internal Policies of the EU Parliament, called for attention to a participatory design approach and user-defined desiderata around RAS in care applications [4].

The main questions addressed here are thus: (1) what are the challenges for robots in the health and social care sector according to european communities? and (2) what are the perceived implications of technologies proposed to address these? Addressing these questions will help guide designer groups, entrepreneurs, and governmental organizations in their effort to create robots to support carers and patients according to their needs. Moreover, it could motivate researchers to continue or start projects that address the technological challenges.

To this end, we identified RAS care challenges seen by health and social care stakeholders - health and social care professionals, patients and service users, and students - in Cornwall (UK) [5]. So that participants could better understand opportunities and limitations of RAS, we ran workshops including first a technology showcase in which particiants had the opportunity to interact with some of the most representative assistive technologies currently available and then participants were allocated and took part in focus groups. 


\section{Background and Previous Research}

We begin by describing some of the existing applications of RAS in health and social care. We do not aim for an exhaustive review, but focus on representative studies that illustrate the current state of the art, in particular with respect to the exploration of user needs.

\subsection{Present-day application domains of RAS}

RAS have a wide range of application domains in health and social care, and and have been developed and evaluated in various research projects (Table 1). Mostly, the effort focuses on the automation of activities of daily living, such as reaching and manipulating objects, and assisting user mobility and selfcare. For instance, there are robotic arms capable of attaching to wheelchairs [6], or assisting a person with their personal care [7] as well as modular robots that move around a users' house using a rail system of hoists for transferring people [8], and robotic shower systems to assist frail persons [9].

Exoskeletons are used in the recuperation process of patients with severe muscular dystrophies or as walking aids [10] while robotic assistant platforms are used to set alarms [11], remind people to take medication [12], provide real-time information [13], and to promote healthy habits or behaviour change therapy [14], for instance, to encourage exercise [15].

RAS further have applications in addressing social isolation. For example, the robot seal Paro has been shown to reduce loneliness among old people [16], and to improve mood, anxiety, and quality of life [17].

Telepresence robots promote social interaction [18], while supporting remote diagnosis and monitoring of patients.

In sum, the application domains of RAS are rich and varied, and RAS have the potential to change the way we perceive and treat a range of impairments and conditions, and how we actively support those in need [2].

Table 1. Examples of RAS in health and social care.

\begin{tabular}{llll}
\multicolumn{1}{c}{ Robot } & \multicolumn{1}{c}{ Description } & \multicolumn{1}{c}{ Benefits } & \multicolumn{1}{c}{ Status } \\
\hline JACO 3 & $\begin{array}{l}\text { Robotic arm that can be installed in } \\
\text { any electric wheelchair }\end{array}$ & $\begin{array}{l}\text { Support activities of daily living (i.e.: drinking from } \\
\text { glasses, opening doors, picking up objects, scratch- } \\
\text { Fingers [6] }\end{array}$ & $\begin{array}{l}\text { Commer- } \\
\text { cially availa- } \\
\text { ble }\end{array}$ \\
ASIBOT & $\begin{array}{l}\text { Robotic arm that can operate in bath- } \\
\text { [7] }\end{array}$ & $\begin{array}{l}\text { Support with self-care (i.e.: shaving, brushing their } \\
\text { teeth, cutting their hair, putting make-up. })\end{array}$ & $\begin{array}{l}\text { Laboratory } \\
\text { research state }\end{array}$
\end{tabular}




\begin{tabular}{|c|c|c|c|}
\hline JUVA [8] & $\begin{array}{l}\text { Modular robot which moves around } \\
\text { houses using the standard rail system } \\
\text { of hoists }\end{array}$ & $\begin{array}{l}\text { Support transferring people (i.e.: stand up from bed, } \\
\text { move around home) }\end{array}$ & $\begin{array}{l}\text { Laboratory } \\
\text { research state }\end{array}$ \\
\hline $\begin{array}{l}\text { I- } \\
\text { SUPPORT } \\
{[9]}\end{array}$ & $\begin{array}{l}\text { Robotic shower system to assist frail } \\
\text { persons }\end{array}$ & Support with self-care & $\begin{array}{l}\text { Laboratory } \\
\text { research state }\end{array}$ \\
\hline [19] & $\begin{array}{l}\text { Robotic system that will provide ac- } \\
\text { tive support for dressing }\end{array}$ & Assistance with Dressing & $\begin{array}{l}\text { Laboratory } \\
\text { research state }\end{array}$ \\
\hline Obi [20] & Robotic arm that support feeding & Support activities of daily living & $\begin{array}{l}\text { cially availa- } \\
\text { ble }\end{array}$ \\
\hline $\begin{array}{l}\text { Cyber- } \\
\text { Legs++ } \\
{[10]}\end{array}$ & $\begin{array}{l}\text { Robotic cognitive orthoprosthesis for } \\
\text { lower limbs }\end{array}$ & Support rehabilitation therapy & Unavailable \\
\hline SEM Glove & $\begin{array}{l}\text { Robotic glove to improve the grip- } \\
\text { ability }\end{array}$ & $\begin{array}{l}\text { Support activities of daily living (i.e.: grabbing } \\
\text { things) }\end{array}$ & $\begin{array}{l}\text { Commer- } \\
\text { cially availa- } \\
\text { ble }\end{array}$ \\
\hline $\begin{array}{l}\text { Cyberdyne } \\
{[21]}\end{array}$ & Upper and lower limb exoskeletons & Support patient mobility & $\begin{array}{l}\text { Commer- } \\
\text { cially availa- } \\
\text { ble }\end{array}$ \\
\hline Buddy [13] & Home robot & $\begin{array}{l}\text { Support activities of daily living (i.e.: medicines re- } \\
\text { minder, real-time information, promoting healthy } \\
\text { habits) }\end{array}$ & $\begin{array}{l}\text { Commer- } \\
\text { cially availa- } \\
\text { ble }\end{array}$ \\
\hline Paro [22] & Robotic seal to reduced loneliness & Reduce loneliness and social isolation & $\begin{array}{l}\text { Commer- } \\
\text { cially availa- } \\
\text { ble }\end{array}$ \\
\hline Leka [23] & $\begin{array}{l}\text { Robotic smart toy for children with } \\
\text { ASD }\end{array}$ & Support social skill therapies & $\begin{array}{l}\text { Commer- } \\
\text { cially availa- } \\
\text { ble }\end{array}$ \\
\hline Cutii $[24]$ & Telepresence robot for old people & $\begin{array}{l}\text { Reduce loneliness and social isolation (i.e.: online } \\
\text { courses) }\end{array}$ & $\begin{array}{l}\text { Commer- } \\
\text { cially availa- } \\
\text { ble }\end{array}$ \\
\hline $\begin{array}{l}\text { FriWalk } \\
{[15] \mathrm{a}}\end{array}$ & Robotic walker & Support patient mobility and rehabilitation therapy. & Unavailable \\
\hline Zipline [25] & Drone for blood bag delivery & Support emergency respond & Unavailable \\
\hline $\begin{array}{l}\text { LUCAS } \\
{[26]}\end{array}$ & $\begin{array}{l}\text { Chest compression system for car- } \\
\text { diac arrest }\end{array}$ & Support emergency respond & Unavailable \\
\hline
\end{tabular}

\subsection{Understanding user needs and supporting key objectives of health and social care using RAS}

Previous work [1][2] has established a roadmap of promising applications of robotics, including RAS, in health and social care. They highlight the potential of RAS to support people to live independently, maintain activity and promote healthy habits. In addition, they describe the crucial role of robots in rehabilitation, medical assistance at home and surgical robots and discuss how 
robots could reduce the burden for carers, mostly in physically demanding activities.

When it comes to assessing user needs, most literature comes from acceptability studies of different socially assistive robots that collected desiderata from their participants (e.g.; [27-30]), but these studies often focus on specific conditions or impairments, or technologies. For example, Huskens et al. evaluated the effectiveness of a robot-mediated intervention based on Lego therapy for children with autism spectrum disorder (ASD) [31], discussing practical implications and directions for future applications around robots as therapy partners for children, and affective computing applications. Pino et al. analysed the attitudes and opinions of persons with mild cognitive impairment towards socially assistive robots [32], concluding that participants acknowledged the potential of RAS in cognitively stimulating and entertainment applications, support of daily tasks, and patient monitoring.

Huijnen et al. explored how a specific technology, the socially assistive robot KASPAR, could be introduced into therapy interventions for children with ASD [33], finding that RAS could be used in social skill therapies, providing communication and social support. Zubrycki and Granosik explored the needs of ASD therapists and found how RAS could improve their work environment [34]. Lehmann et al. explored which parts of everyday life RAS could help old people [14], identifying opportunities for RAS in activities such as housekeeping, compensating cognitive impairment, communication, and isolation. Michaud et al. [35] highlighted the importance of RAS for telemonitoring in homes to decrease health care system load, reduce hospitalization period and improve quality of life and independence.

In terms of evaluating RAS in healthcare, Martin-Ortiz et al., for example, developed different criteria to evaluate end-users' willingness and capacity to use RAS in a healthcare application [36], while Feil-Seifer et al. designed benchmark parameters to measures the effectiveness of RAS systems in the healthcare industry [37]. Both studies outline important social implications for RAS applications, including privacy and ethical issues.

\section{Procedure and Methods}

Motivated by the existing work that focused on a specific condition, impairment or stakeholder, the procedure and methods selected by this study allowed us to explored community needs for RAS in health and social care 
settings without any initial restriction. Furthermore, while most of the previous work relied on video or image-based methods, we gave users the chance to interact physically with the technology they were supposed to explore and assess.

\subsection{Particularities of Cornwall in assessing RAS user needs}

This study took place in Cornwall in the South-West of the United Kingdom. From an economic and population perspective, Cornwall is similar to other less developed regions in Europe (Figure 1), where the necessity to address user needs, perhaps through RAS, is most acute [38]. Cornwall is a thinly populated area (Figure 2) and has an ageing population [39] [40], a primary health and social care challenge of most European countries [41] [2].

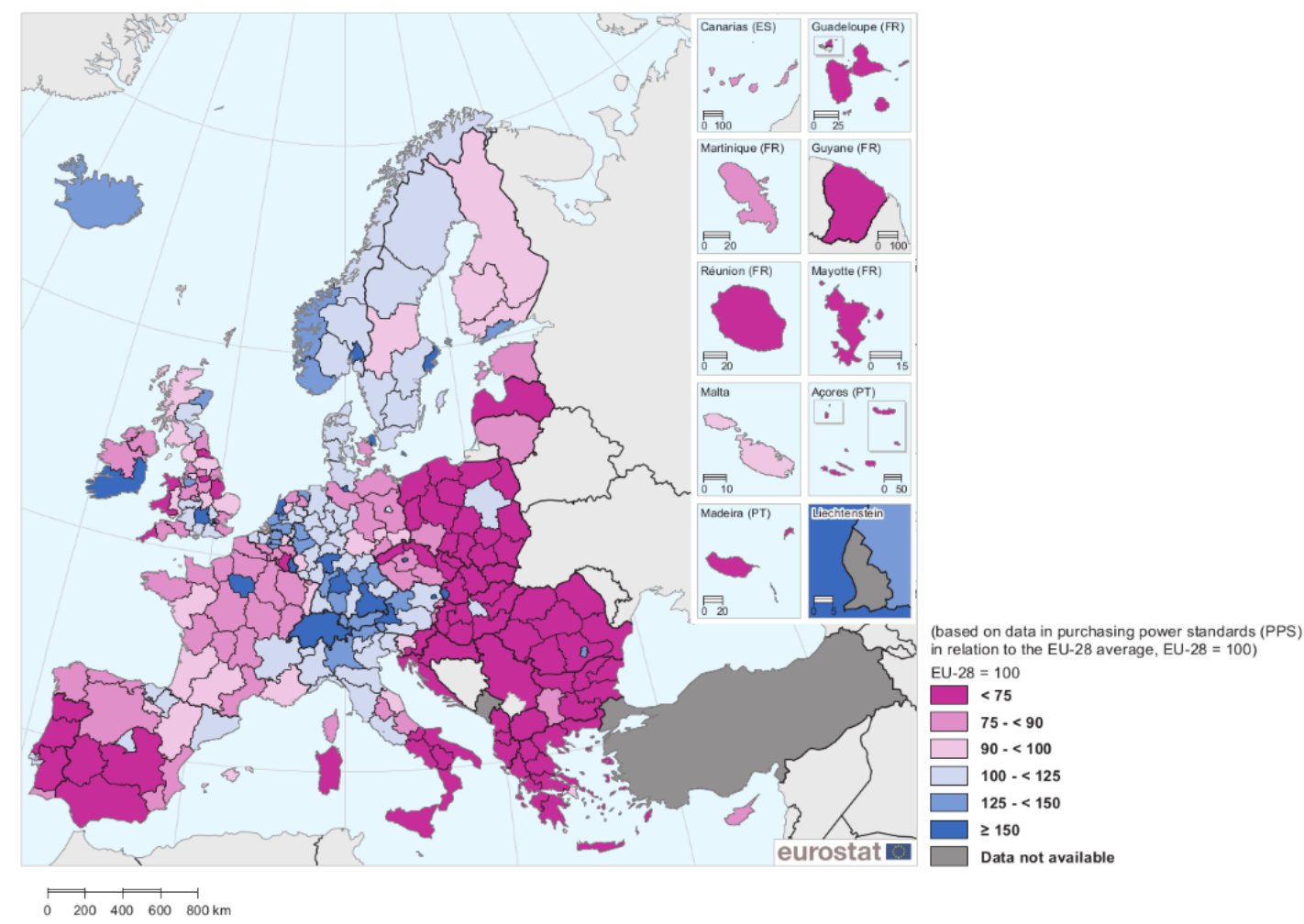

Figure 1. Gross domestic product (GDP) per inhabitant, 2016. Source: Eurostat [38]. 


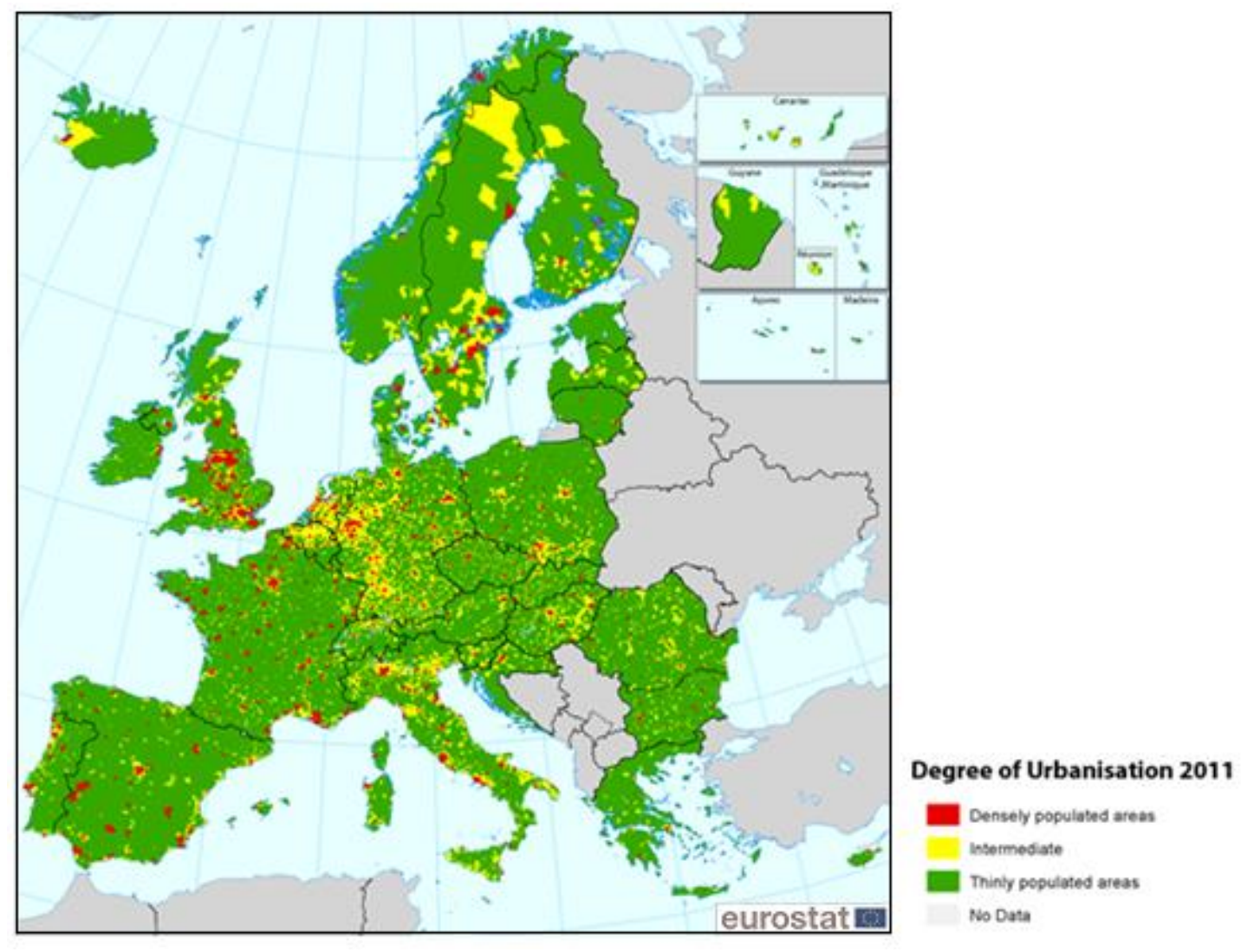

Figure 2. Europe degree of urbanization, 2011. Source: Eurostat [42].

\subsection{Participants}

Participants were recruited, and the workshops organized, by the Ehealth Productivity and Innovation in Cornwall and the Isles of Scilly (EPIC) project [43] so as to gather a representative sample of Cornwall's health and social care community. These workshops, comprising a technology showcase and up to five focus groups (Table 2), were held at eight different locations across Cornwall (Figure 3), giving geographical coverage of the region.

In total, 223 participants with various backgrounds (Table 2) contributed to this study. Health and social care professionals included domiciliary care, residential care, general practice, hospital doctors and nurses, pharmacists, mental health specialists, and health-related charitable organizations. 
Service users were recruited through online advertisements, newspaper articles and advertisements, support groups and public engagement events in some locations took part. Service users were further recruited from Patient Participation Groups from general practitioner (GP) practices. University students from different backgrounds were also recruited via online advertisements and emails. Finally, representatives from small and medium enterprises (SME) related to the healthcare industry were also invited via online advertisement and emails. Table 2 shows that our focus groups had participants from a range of backgrounds so giving a rich interaction.

We were not aware of any participants having been diagnosed with cognitive impairment. The Faculty of Science and Technology Ethics Committee at the University of Plymouth granted ethical consent for the research in September 2017.

Table 2. Participants' classification according to their background.

\begin{tabular}{|c|c|c|c|c|c|c|c|}
\hline \multirow[b]{2}{*}{$\begin{array}{l}\text { Workshop } \\
\text { Location }\end{array}$} & \multirow[b]{2}{*}{$\begin{array}{c}\text { Total At- } \\
\text { tended }\end{array}$} & \multicolumn{5}{|c|}{ Type of participant } & \multirow[b]{2}{*}{$\begin{array}{l}\text { Focus } \\
\text { groups }\end{array}$} \\
\hline & & $\begin{array}{l}\text { Health or social } \\
\text { care professional }\end{array}$ & $\begin{array}{l}\text { Service } \\
\text { User }\end{array}$ & Student & $\begin{array}{l}\text { Small and medium } \\
\text { enterprises (SME) }\end{array}$ & Other & \\
\hline Liskeard & 44 & 16 & 14 & 4 & 3 & 7 & 5 \\
\hline Truro & 36 & 13 & 8 & 5 & 6 & 4 & 5 \\
\hline Redruth & 26 & 17 & 1 & 2 & 2 & 4 & 4 \\
\hline Ludgvan & 22 & 10 & 2 & 2 & 4 & 4 & 4 \\
\hline Newquay & 19 & 12 & 1 & 1 & 0 & 5 & 3 \\
\hline Falmouth & 25 & 10 & 3 & 7 & 1 & 4 & 4 \\
\hline Wadebridge & 24 & 14 & 2 & 0 & 2 & 6 & 4 \\
\hline St Austell & 27 & 16 & 3 & 3 & 2 & 3 & 4 \\
\hline Total & 223 & 108 & 34 & 24 & 20 & 37 & 33 \\
\hline
\end{tabular}




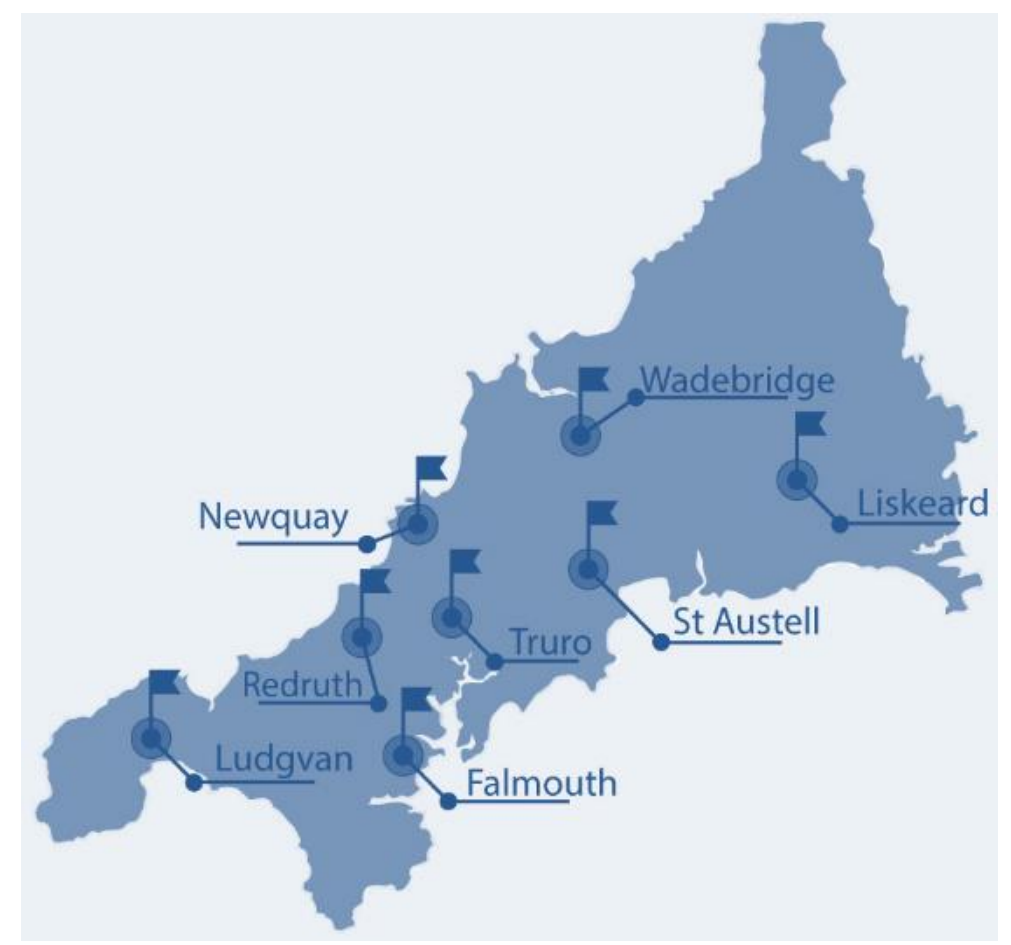

Figure 3. Workshop locations.

\subsection{Technology showcase}

All workshops began with a technology showcase with two sections: robotics and apps/virtual reality, including home, and smart toys. The robotics showcase involved a large room containing various technology stations at which participants were invited to visit and interact with the technology.

Four different robots were presented to participants (Figure 4): Pepper and Paro are commonly used examples of socially assistive robots [19-23]. Miro is being evaluated for its potential as a robot companion at home, and for applications in robot-assisted therapy [2]. Finally, Padbot is a commercially available telepresence robot used to explore how RAS could address social isolation issues. 


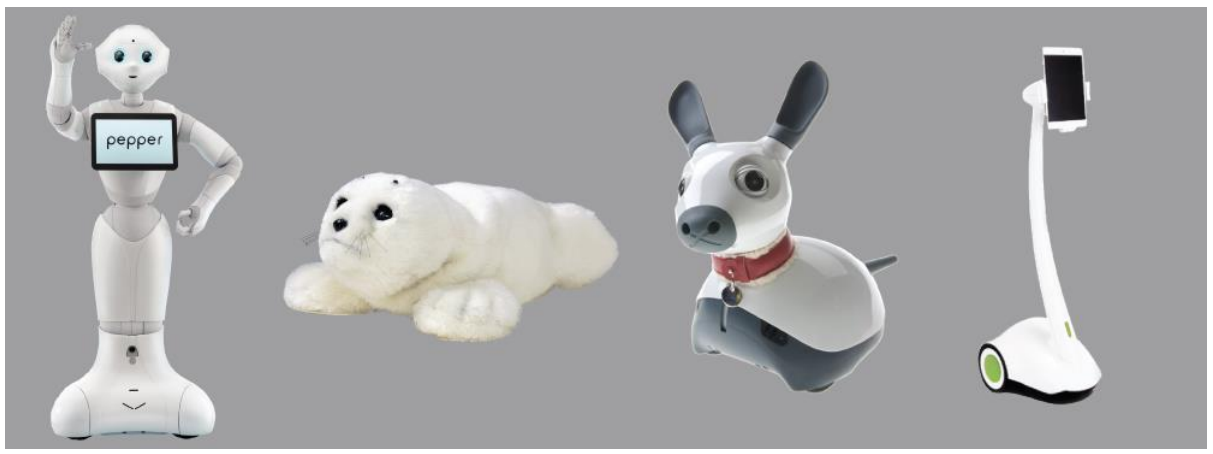

Figure 4. Robots presented in the showcase and design category: (from left)

Human-like, Pepper; Animal-like, Paro and Miro; Machine-like, Padbot.

This initial showcase session lasted 40 minutes. Participants approached stations voluntarily, and researchers provided information and demonstrations of the technology. General robot features, such as size, autonomy, weight, and interaction modalities were presented. Participants were given the opportunity to interact with the robots themselves. With each robot, several use-case scenarios were presented to explore the uses of present-day socially assistive robots.

\subsection{Focus Groups}

Focus groups [47] in which the different types of stakeholder can interact were considered the best way to explore views and identify current and emerging issues in the health and social care sector [48]. Participants can develop their ideas together, stimulating idea generation and dialogue guided by a facilitator. After the showcase, participants joined an allocated break-out focus group (Table 2). Each group comprised of 4-10 people and was facilitated by a team member from EPIC with a colleague keeping notes on a standard proforma (Appendix). The task set for each group was to identify areas where they thought that digital technologies, including apps and RAS, might provide the basis of a 'solution'.

First, all groups listened to an overall presentation. The presentation included: a video introduction of the EPIC project, the aims of the focus groups, examples of eHealth solutions such as the telepresence robot Giraff and internet of things applications. 
Facilitators then started their focus groups by asking broad questions about the participants' backgrounds and primary concerns. Participants were encouraged to explain daily life challenges that they, their patients or relatives face, and to imagine possible solutions, including RAS that could help them solve those problems. Once participants had described their challenges, facilitators moved the group discussion onto exploring possible solutions by asking the participants questions such as "Do you have any idea of technology solutions?", "What is the nature of the technology?", and "How do you want it to help?"'. Each challenge had different levels of suggested solutions for the problems raised, design aspects, and conditions for technology adoption.

Group discussion encouraged respondents to explore and clarify individual and shared perspectives, benefiting from the multidisciplinary nature of the groups [24-26]. The discussion lasted 100 minutes.

Finally, the facilitator and scribe for each group identified up to five challenges while with the group and summarised these themes in a short paragraph. For the purpose of this analysis, we have used the themes written by the facilitators. From the focus groups, we identified 163 challenges.

\subsection{Data Analysis}

The analysis builds upon Thomas' general inductive approach for analysing qualitative data, comprising of three main stages; search, evaluation, and classification [49]. First, an open coding system was used on the 163 challenges to search for suggested solutions recorded that explicitly or implicitly referred to RAS using the query tool of Nvivo 11 [50], qualitative data analysis (QDA) computer software. The result from this stage was a sub-list of 87 challenges.

Second, all 87 identified challenges were evaluated individually to validate that they represented possible robotic applications. Two researchers (GA, HB) read the 87 challenges and assessed if they had or not an explicit robotic solution. Nine challenges were excluded leaving 78 challenges for RAS for further analysis.

Finally, we ran a standard cluster analysis of all the 78 challenges for RAS using the cluster analysis tool of Nvivo 11 software to combine similar ideas [50]. From the NVivo cluster analysis-dendrogram (Figure 5) we defined three main groups represented there by the upper branches: independent, rurality and isolation. In each group, we can see the most frequent 
themes. For instance, monitoring and medication were mentioned mostly around the main rurality issue. Figure 6 shows the NVivo tag cloud of all the themes mentioned. These three main groups, hereinafter referred to as opportunities for RAS, are described in the next section.

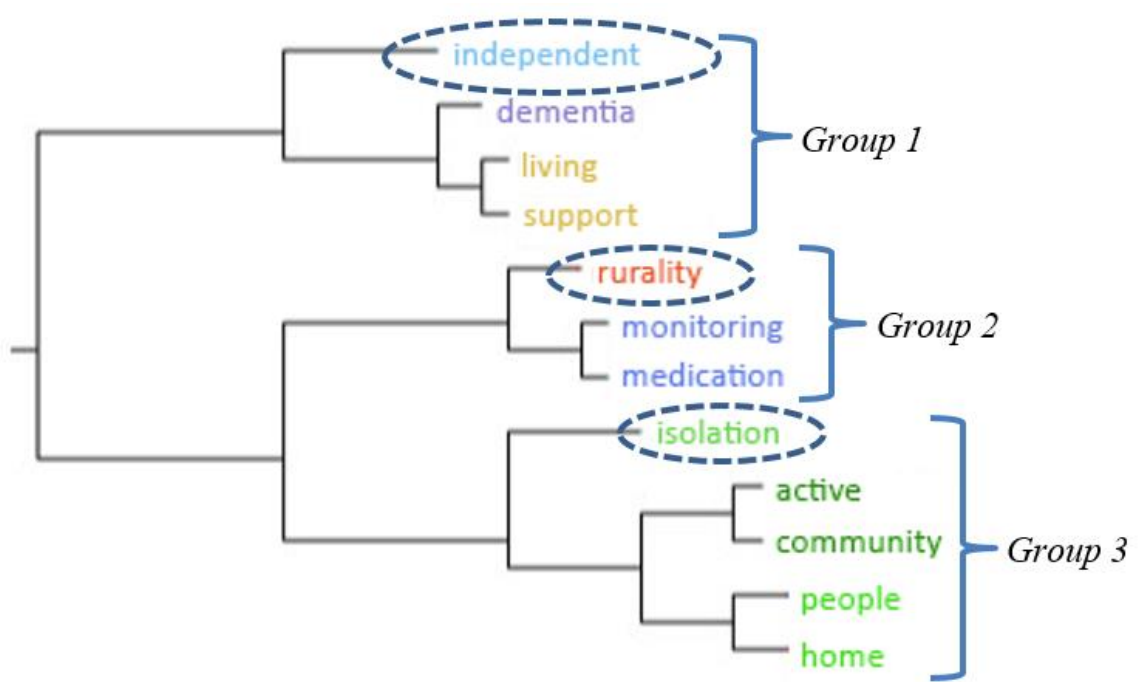

Figure 5. NVivo cluster analysis-dendrogram using Pearson correlation coefficient. From which we defined three main groups: independent, rurality and isolation. 


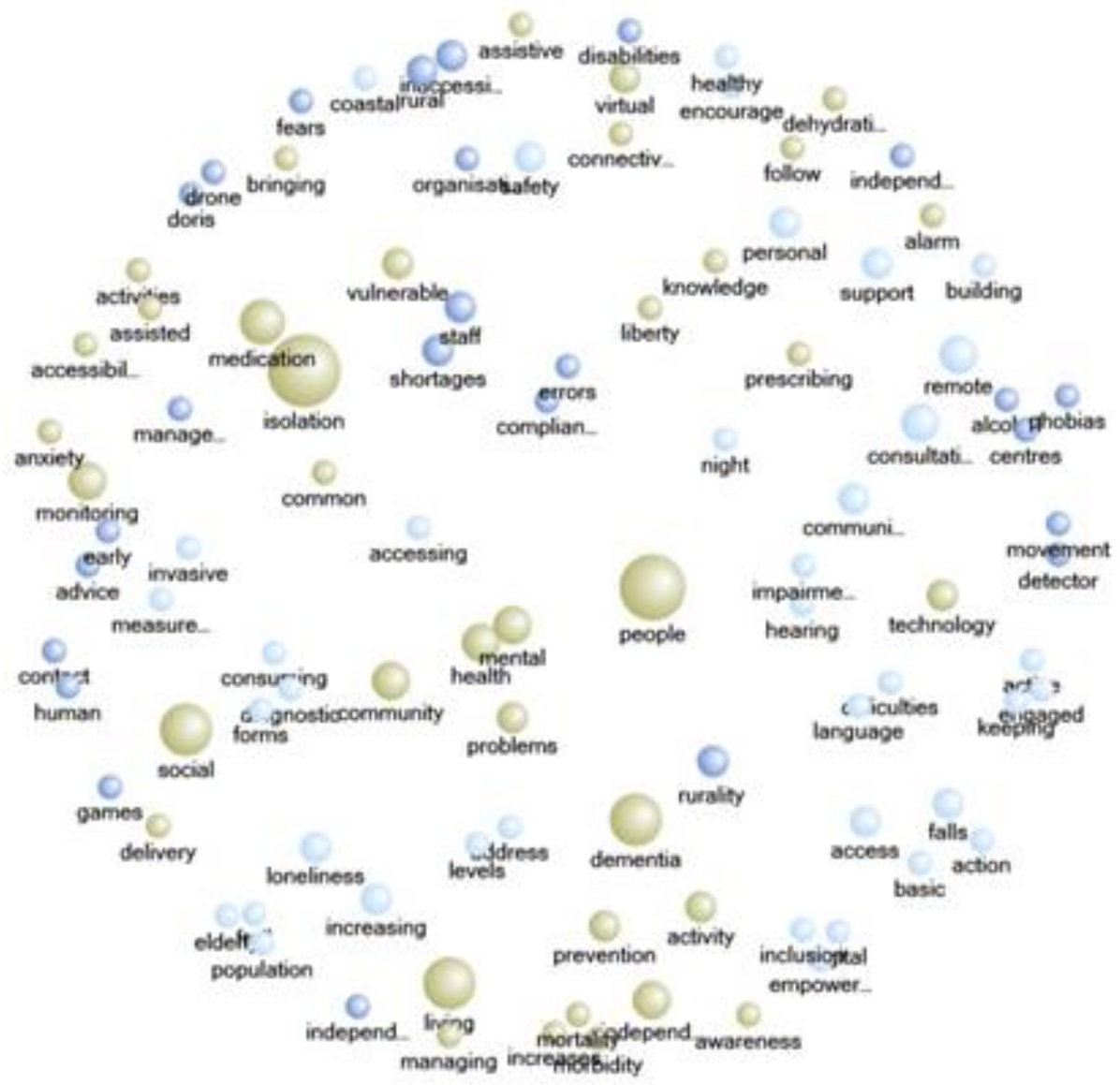

Figure 6. NVivo tag cloud showing the themes mentioned around the three main groups; blue; rurality, sky-blue; independent, and brown; isolation.

\section{Results}

The 33 focus groups produced 163 main challenges overall, of which 78 were relevant to a robotic solution. They were analysed and classified into three main opportunities for RAS in the health and social care sector; maintaining independence at home (36), social isolation (20), and rurality (22). Figure 7 shows that discussions in 6 of the 8 locations were varied; they did not have a predominant topic. Also, after the analysis, two locations (Newquay and St Austell), did not produce desiderata in one of the three main opportunities. 


\section{RAS opportunities recorded per location}

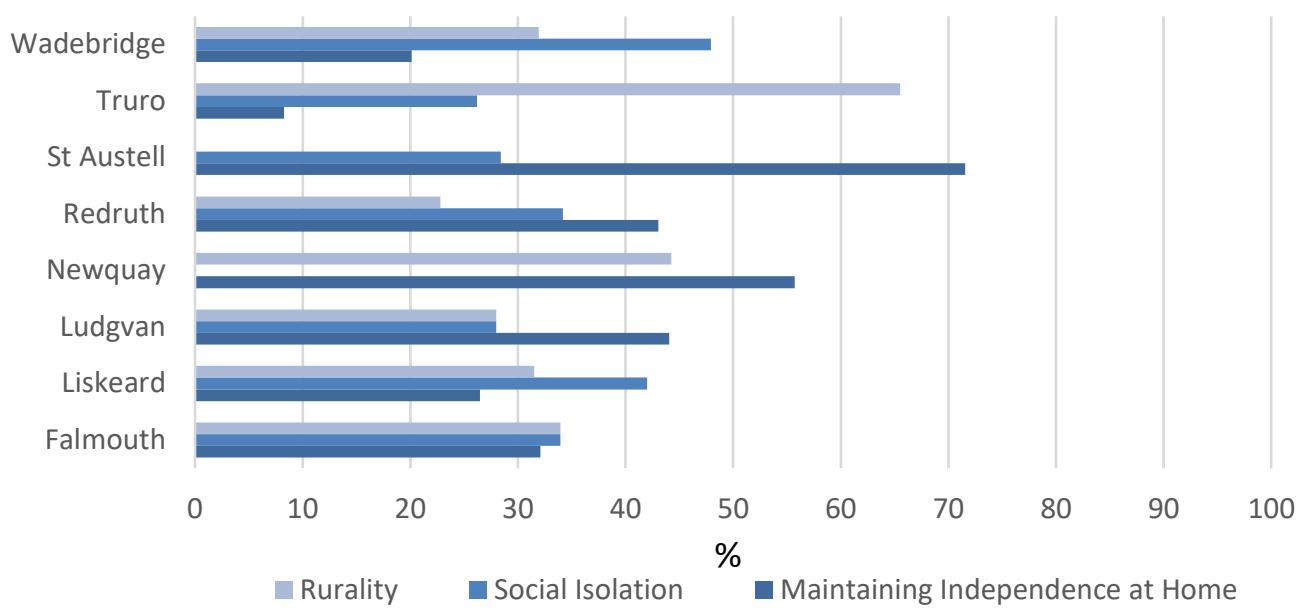

Figure 7. Distribution of the three main opportunities for RAS as recorded at each location

\subsection{Maintaining independence at home}

Developing and maintaining the capabilities that empower all people to be and do what they value in their own homes was one of the leading robotic opportunities identified by focus group participants. Three vulnerable groups were identified and discussed.

The first vulnerable group comprised people with cognitive impairment resulting from dementia, traumatic brain injury or stroke who struggle to live independently. Examples of problems included people forgetting to turn off the oven after use, disorientation, mobility problems, dressing and undressing. Other examples included issues with patients being unable to remember to take their medicines, keeping themselves hydrated, or remembering appointments. Participants discussed how this dependence leads to an increasing burden on social care services.

The second group comprised people who require over-night support. This includes patients who suffer from night rumination, anxiety, or epilepsy. Participants said that this group needed one-to-one support and 'wakingnights'. This limited independence creates more workload for social care services, which NHS commissioners find expensive and difficult to arrange. 
Finally, people who lived with a chronic condition or disability, including people with learning disabilities, were the third most frequently discussed vulnerable group. They were considered to need help around the house to carry out essential activities of daily living, from reaching and getting objects, to using everyday appliances such as washing machines or TVs.

To address these issues, participants suggested some dedicated robotic solutions: from robotic arms to help patients reach objects, to walking aid robots and automatic hoists to lift users. Table 3 presents the summary of activities that participants considered that robots could support to help those in need to have more independent lives.

For instance, they mentioned the possibility of using robotic animals for helping vulnerable users move around their homes, giving them directions while leading the way. Furthermore, participants discussed robots that could prompt a person to do a task such as switch off the tap or take medication. They could also help vulnerable groups use current technology, for example, an oven or a microwave, by providing visual cues for the user while monitoring their progress. They further considered robots that could identify objects for sight-impaired people. These systems would not only support independent living, but it was mentioned they would also help vulnerable group in " $a d$ dressing independence reassurance seeking".

Participants also acknowledged the potential of robots' computer vision features like motion detection and behaviour analysis, by mentioning they would trust robots monitoring patients. For example, they suggested a system to measure the therapeutic levels of epilepsy medication. By analyzing the patient behaviour using a non-intrusive video system, autonomous systems could identify daily changes and produce a risk-level assessment of seizure each night; "this will allow high or low alert support, and for medication tweaking if needed". Other examples, such as unwitnessed falls detection, wandering or even physical abuse detection were mentioned. Mood and emotion monitoring were also suggested as one useful tool to identify triggers, provide helpful prompts, and early de-escalation of abnormal activities. The examples suggested by participants show the willingness of our health care stakeholders to consider using autonomous systems monitoring patients.

Besides supporting activities of daily living, participants also considered the importance of robots encouraging users to exercise, for example, by following the lead of the robot in a different range of physical activities while the system makes an assessment of various parameters such as the patient's 
gait and balance, or even stroke rehabilitation assessment of movement. They also considered this technology could play a role in persuading families to eat healthier. Such activities would benefit health and self-management.

Finally, participants agreed that the mentioned robotic solutions would reduce burden and worry for caregivers and families. By using telepresence robots, participants declared that doctors could monitor the living conditions of vulnerable people. This technology was considered useful to assess patients living alone, while not disturbing their independence or deploying health professionals unnecessarily; "one member of staff could then oversee and support a number of houses".

\subsection{Social Isolation}

Social isolation is the absence of contact between an individual and society. Isolation not only occurs because of geographic remoteness but also within care homes as recorded by our focus group participants. The new environment can be daunting for old people, leaving them feeling excluded from the outside world and alone, despite being surrounded by other residents.

Moreover, it was identified as an effect of experiencing a long-term condition causing slow cognitive decline. Health deterioration, as the progression of dementia, can cause a disconnection from reality. This causes confused residents to withdraw from their healthy hobbies and social events, reducing their quality of life. Also, isolation can increase the workload on health and social care services and affect their working environment.

Participants suggested solutions involving the use of social and therapeutic robots. Paro and Miro were discussed for their perceived ability to entertain the user. Participants mentioned that these robots not only bring reassurance and 'connection' but also could help calm people in distress, reducing agitation and anxiety in patients, and could motivate people and cheer them up.

Other applications discussed included voice recognition of robots to engage in conversation with isolated patients. Participants agreed that humanrobot conversations might be a useful feature to reduce patients' loneliness. For example, patients with different level of dementia could benefit from humanoid robots, engaging in conversations. Participants did not view this as an ethical predicament. It was also considered an opportunity to integrate people. For example, participants thought that care home residents would interact 
more with each other and the caregivers because of the robots. Furthermore, some thought this involvement of robots would help raise the esteem of care home staff.

Human-robot conversations can also benefit people with learning difficulties. Regarding Pepper's tablet and voice recognition system, for example, a participant mentioned that "people on the autistic spectrum could struggle with this screen so that they would rely on voice commands". This exemplifies the importance of developing platforms with multiple options of user interface. This was also supported by numerous comments about old people struggling to hear Pepper, but finding the communication proposed by the robot through its tablet adequate. Several people further mentioned the importance of the robot being able to talk in the same accent.

Additional opportunities were discussed. Therapy sessions were considered a useful way of employing robots. The entertainment element that these robots can provide was also regarded as beneficial. The live streaming of physical activity classes, music performance, storytelling or the possibility of retrieving memories using these technologies was deemed to be advantageous. They added that robots might engage the community i.e. motivating family members such as young children to visit residents. Therefore, it was considered useful that robots should have dynamic applications for patients and family members to interact as well, for example, a different range of interactive games.

Finally, this problem also brings an opportunity for telepresence robots. The ability to remotely control these robots, plus features like auto answering and collision detection were thought useful by participants. They considered the telepresence robot as a useful tool for families to keep in touch and avoid social isolation. Furthermore, participants mentioned that robots could have a significant role connecting society in the future (Table 3 ).

\subsection{Rurality}

Distance to services, in particular, specialist services, lack of access to care, and the sparse population served was raised in nearly every focus group.

For example, nurses in care homes find it challenging to get hold of a GP when residents are unwell. Participants discussed how healthcare professionals and caregivers' burnout contribute to this problem. Furthermore, rural- 
ity is not only a problem of access to care but also to medications or emergency treatment. The example of a cardiac arrest on a beach was cited with the problems of being located on the moors or coastal paths.

The first robotic solution suggested was the use of telepresence robots. Using video calls, participants identified a viable link between GPs, paramedics, care homes, and patients. Doctors or paramedics could carry out a digital consultation being able to see the patient and assess their condition. For all of these, participants discussed including systems in these devices that allow physical readings such as blood pressure. Furthermore, these devices should enable GPs to move around freely, give them reliable images of the patients, and the option to physically interact with patients for a complete inspection. Finally, RAS could run, during the calls, visual health screening of the patients to identify any visible symptom of a disease or condition, to support the health assessment of the caller.

To address the challenges of access to medicine and emergency treatment, some healthcare professionals thought the use of drones useful. Participants suggested drones carrying medical equipment to first responders. Medication delivery could also benefit from this technology (Table 3 ).

RAS could also offer first aid to some unpredictable events. For instance, if the user suffers a minor injury, such as a broken arm, the robotic platform could immobilize the user limb to prevent further damage, until the user could get professional support. It could also be used to stop bleeding or give medications, such as those that are delivered through intravascular infusion. Besides, RAS active sensing systems could help users understand what their medical symptoms could mean.

Table 3. Summary of user-led challenges and desiderata for RAS.

Maintaining independence at home

Social Isolation Rurality

\begin{tabular}{llll}
\hline $\begin{array}{l}\text { Accessing the bath } \\
\text { Sitting on the toilet }\end{array}$ & $\begin{array}{l}\text { Starting and keeping conver- } \\
\text { sations }\end{array}$ & $\begin{array}{l}\text { Platform for GPs video call } \\
\text { and teleoperation }\end{array}$ \\
$\begin{array}{l}\text { Self-care assistant } \\
\text { Creating emotional links } \\
\text { with the user }\end{array}$ & $\begin{array}{l}\text { Interactive } \\
\text { checker }\end{array}$ & symptom \\
Assisting with white goods. & $\begin{array}{l}\text { Reducing agitation and anx- } \\
\text { iety }\end{array}$ & $\begin{array}{l}\text { Automatic GP schedule } \\
\text { appointment }\end{array}$ & \\
& Motivating users &
\end{tabular}




\begin{tabular}{lll}
\hline $\begin{array}{l}\text { Switching off/on devices } \\
\text { Reaching things }\end{array}$ & $\begin{array}{l}\text { Bringing patients together } \\
\text { Raising esteem of caregivers }\end{array}$ & $\begin{array}{l}\text { Delivering information of } \\
\text { the healthcare system }\end{array}$ \\
Lifting heavy things & $\begin{array}{l}\text { Developing user socializa- } \\
\text { tion skills }\end{array}$ & $\begin{array}{l}\text { On-call health monitoring } \\
\text { systems }\end{array}$ \\
Cleaning & $\begin{array}{l}\text { Entertaining patients and } \\
\text { families together }\end{array}$ & First aid response \\
Reminder of medication & Video calls services & $\begin{array}{l}\text { Medication delivery and } \\
\text { administration }\end{array}$ \\
Dressing & & \\
Waking-night support & & \\
Indoor guidance support & & \\
Moving around & & \\
Promoting healthy habits & & \\
Health screening & \\
Mood and emotion monitoring & \\
Entertainment
\end{tabular}

\section{Discussion}

The desiderata identified by the participants of the focus groups were classified in three main groups (Table 3), which, in line with the key findings of $[1,2]$, have demonstrated the main opportunities for RAS to support daily life activities and reduce social isolation. By accomplishing this; participants felt that robots could empower people to stay in their homes, improving user quality of life (see also [51]). RAS were also seen as a way of addressing independence reassurance seeking, having a further impact on care.

\subsection{Maintaining independence at home}

In line with [32,52], most challenges we identified around maintaining independence at home referred to activities such as reaching and manipulating things or assisting user mobility and self-care. While Table 1 shows different effort for addressing these challenges, there remain non-addressed implications. For instance, participants of our focus groups were concerned about safety parameters [37,53]: declining hand-eye coordination, tremors, or 
loss of hand dexterity might affect control of robotic arms. Participants discussed that this could not only harm the patients but also the people around them.

Similarly, most challenges involve close physical interaction between robots and users, as dressing or bathroom aids. Current robots often are not sufficiently safe to operate physically with people [2]. Therefore, advances are required in high-performance actuators, tactile sensors, grippers, and manipulation.

Research is also needed in cognitive robotics: to deploy robots that will help people remain in their homes requires them to be able to operate in that environment. This requires advances in locomotion abilities, active sensing systems, and, more generally, artificial intelligence. For example. RAS must be capable of mapping and understanding dynamic human environments, various and varying light conditions, and the full range of designs, shapes, and colours of everyday objects.

Applications promoting healthy habits were also mentioned (as in, for example, [14]). Furthermore, per [34], we found that healthcare professionals were interested in employing robots that could reduce their workload, not only in bureaucratic activities, but in directly engaging with the patients (in contrast with more sceptical findings from [54] where practitioners were questioned about robots replacing them). Participants also saw RAS as tools for raising the self-esteem of caregivers, in line with [44].

Moreover, in contrast with [55,56], our participants showed a predisposition towards autonomous systems for monitoring patients, including the use of non-intrusive cameras for patient surveillance not only improve patient safety and reduce carer's workload, but also as a way to improve response time. For instance, they were not concerned with Pepper's cameras and said that they did not perceive their privacy to be affected. This may be the result of the physical interaction participants had with robots during the technology showcase. First-hand interactions have been found to improve people attitudes towards and preconceptions of RAS [57]. It also highlights the importance of ensuring that cameras and their respective memory systems operate transparently, respecting user rights, and providing options to manage when and what is stored [58]. 


\subsection{Social Isolation}

Moving to the desiderata collected around social isolation, most of the applications identified by the participants were also in accordance with the findings of previous research [35]. For instance, previous research identified RAS to reduce agitation and anxiety [17] and to develop social skills [33] as participants suggested (Table 3).

The most interesting finding was participants' acceptance of using robots as a way to create emotional links with users. In contrast with other studies [59], participants were not concerned with ethical predicaments in using humanoid robots like Pepper or fake pets such as Paro to comfort and provide company for care home residents. Again, this could be a result of the participants actually interacting with the RAS at the beginning of the focus groups.

However meeting some of the social isolation challenges that were raised requires improvements in automatic speech recognition. For example, noisy environments, places with echo, or even big rooms, affect Pepper's automatic speech recognition, and this is seen as a limitation by the study participants. Automatic speech recognition must also support a broader range of voices, accents, intonation, dialects, and non-verbal communication. Finally, studies have shown that despite the improvement in adult speech recognition, children's speech recognition does not work reliably, and more research is needed [60].

\subsection{Rurality}

Finally, desiderata on rurality can be related to previous work $[35,61,62]$, for example, telepresence robots for telemedicine applications, such as video call GP consultation and scheduling appointments [63]. The challenges of delivering medicines, identified in our focus groups, have been studied by others [64] exploring the positive effect in the downstream healthcare supply chain, and on the direct treatment, promoting positive emotions during medicine intake [65]. Emergency response has also been identified by [66] as a future directions for RAS.

Nevertheless, despite some commercial solutions in the market (Table 1), most of these robotic platforms are currently unavailable for most countries. For instance, Zipline or Lucas are only being used in Rwanda and US respectively. 
While robotic consultations are suggested as a solution for some challenges around rurality (Table 3), participants mentioned challenges in fitting these into existing working practices, the skills needed to run the equipment, the bandwidth in rural areas, and key technologies for the domain of the application of robotics in healthcare such as motion control or collision avoidance.

Overall, the biggest concerns by the participants for RAS around the three main applications was cost. As other studies have found [37], current robots are not affordable for most end users, even considering that healthcare systems around the world have different budgets for financial incentives to adopt new technologies. For example, the cost of Paro, at around $£ 5000$ to $£ 6000$, was considered unaffordable, and had a negative impact on participants' acceptance of RAS. Therefore there is a need to make technology financially more accessible.

\section{Conclusion}

We presented desiderata and challenges for RAS in health and social care settings, identified by all key stakeholders. We collected these using a participatory research strategy through workshops including a technology showcase followed by focus groups.

Our main findings are in agreement with previous research. A noteworthy exception was that participants were not as concerned with ethics or privacy issues for the applications they proposed. Nevertheless, several implications were also identified. Our goal is to raise awareness of these desiderata, and the resulting potential applications, opportunities and implication for RAS.

Although we presented a comprehensive evaluation of user needs, further research is needed, in particular in other types of regions. Large cities, for example, represent $17.8 \%$ of the total EU population [67] and may present different challenges to the rural areas considered here. 


\section{Acknowledgements}

Katie Edwards organized the workshops, recruited participants, helped in the demonstration of technology and engagement of participants, facilitated focus groups, helped compile data from focus groups, read and agreed to the final paper.

Michael Paisey (project manager) managed the EPIC team, worked with Katie Edwards in organization of focus groups, facilitated focus groups at the focus group, contributed to the compilation of data from the focus groups, read and agreed to the final paper.

Tracie North and Heather Eardley (Patients Association) helped in the running of the focus groups, helped in recruiting participants, facilitated focus groups, read and agreed to the final paper. Daniela Austin, Cito Maramba, Deborah Shenton (Research Assistants) and Clare Wyatt (PhD student) helped in the running of the focus groups and roadshows, helped in recruiting participants, facilitated focus groups, read and agreed to the final paper. Lisa Allwood (Administrator) helped in the organization of the workshops. Sheena Asthana, Rod Sheaff, Jackie Andrade, Jon May, Arunangsu Chatterjee, Craig Newman, Kim Young were co-applicants on the EPIC proposal, read and agreed to the final paper.

Andreas Walmsley, PhD co-supervisor of Gabriel Aguiar, read, actively contributed to the writing of the paper, and agreed to the final paper. Angelo Cangelosi (Professor in Robotics) was a co-applicant on the EPIC proposal and advised Ray Jones on the purchase of robots.

\section{Disclosure statement}

No potential conflict of interest was reported by the authors.

\section{Funding}

This work was supported by the Ehealth Productivity and Innovation in Cornwall and the Isles of Scilly project (project reference 05R16P00385) which 
was awarded funding of $£ 2,730,513$ by the European Regional Development Fund. Additional financial for the EPIC project is from the South West Academic Health Science Network and University of Plymouth.

\section{References}

[1] Butter M, Rensma A, van Boxsel J, et al. Robotics in Helthcare, Final Report. Robot. Helthcare. 2008;179.

[2] UK-RAS. Robotics in Social Care: A Connected Care EcoSystem for Independent Living [Internet]. EPSRC UK-RAS Whitepaper. 2017 [cited 2017 Oct 25]. Available from: www.ukras.org.

[3] EUrobotics. Robotics 2020 Multi-Annual Roadmap. EUrobotics. (2015). Robot. 2020 Multi-Annual Roadmap, 2017, 178-228. Retrieved from http//www.eurobotics.net/cms/index.php?idcat=170\&idart=2016 [Internet]. 2017 [cited 2018 Aug 17];2017:178-228. Available from: https://www.eurobotics.net/cms/upload/topic_groups/H2020_Robotics_MultiAnnual_Roadmap_ICT-2017B.pdf.

[4] Nevejans N. European Civil Law Rules in Robotics. Dir. Intern. Policies Policy Dep. C Citizens' Rights Const. Aff. [Internet]. 2017 [cited 2017 Nov 12];34. Available from:

http://www.europarl.europa.eu/RegData/etudes/STUD/2016/571379/IPOL_STU\%282 016\%29571379_EN.pdf.

[5] European Commission. eHealth Action Plan 2012-2020 -Innovative healthcare for the 21 st century [Internet]. 2012 [cited 2017 Oct 25]. Available from: https://ec.europa.eu/health/sites/health/files/ehealth/docs/com_2012_736_en.pdf.

[6] KINOVA. Robot arms - Kinova : Kinova [Internet]. [cited 2018 May 3]. Available from: http://www.kinovarobotics.com/assistive-robotics/products/robot-arms/.

[7] Armada M (Manuel), Sanfeliu A, Ferre M. ROBOT2013: First Iberian Robotics Conference [Internet]. Springer S. 2014 [cited 2018 May 7]. Available from: http://link.springer.com/10.1007/978-3-319-03413-3.

[8] CHIRON. CHIRON [Internet]. 2016 [cited 2018 May 13]. Available from: https://chiron.org.uk/.

[9] I-SUPPORT. i-support project - A service robotic system for bathing tasks [Internet]. [cited 2018 May 3]. Available from: http://www.i-support-project.eu/.

[10] Enrico C. CYBERLEGs Plus Plus [Internet]. 2017 [cited 2018 May 8]. Available from: http://www.cyberlegs.eu/the-project/.

[11] JIBO. Jibo [Internet]. [cited 2018 May 11]. Available from: https://www.jibo.com/.

[12] OLLY. Olly, the world's first robot with personality [Internet]. [cited 2018 May 11]. Available from: https://heyolly.com/.

[13] BlueFrog Robotics. BUDDY - [Internet]. [cited 2018 May 11]. Available from: http://www.bluefrogrobotics.com/en/buddy/. 
[14] Lehmann H, Syrdal D, Dautenhahn K, et al. What Should a Robot do for you ? Evaluating the Needs of the Elderly in the UK. Interactions [Internet]. 2013 [cited 2018 Mar 19];83-88. Available from:

https://s3.amazonaws.com/academia.edu.documents/44104430/What_should_a_robot_ do_for_you_-_Evaluat20160325-27884-

1rw9b94.pdf?AWSAccessKeyId=AKIAIWOWYYGZ2Y53UL3A\&Expires=1521310 294\&Signature=v\%2BlzY7cgmpNrJoXSFICxun7DGrg\%3D\&response-contentdisposition=inli.

[15] ACANTO. ACANTO | ACANTO [Internet]. [cited 2018 May 12]. Available from: http://www.ict-acanto.eu/.

[16] Robinson H, MacDonald B, Kerse N, et al. The Psychosocial Effects of a Companion Robot: A Randomized Controlled Trial. J. Am. Med. Dir. Assoc. [Internet]. 2013 [cited 2018 May 13];14:661-667. Available from: http://robotics.auckland.ac.nz/wpcontent/uploads/2013/07/2013-Paro-loneliness-RCT.pdf.

[17] Moyle W, Cooke M, Jones C, et al. Exploring the Effect of Companion Robots on Emotional Expression in Older Adults With Dementia. J. Gerontol. Nurs. [Internet]. 2013 [cited 2018 Mar 19];39:47-53. Available from: https://www.ifa-fiv.org/wpcontent/uploads/2015/11/PARO-JGN.pdf.

[18] Kristoffersson A, Coradeschi S, Loutfi A. A review of mobile robotic telepresence. 2013;2013.

[19] I-DRESS. I-DRESS Project [Internet]. [cited 2018 May 7]. Available from: https://idress-project.eu/.

[20] OBI. Obi | Robotic feeding device designed for home care [Internet]. [cited 2018 May 3]. Available from: https://meetobi.com/.

[21] Anatomical Concepts. SEM Glove - Anatomical Concepts (UK) [Internet]. [cited 2018 May 8]. Available from: https://www.anatomicalconcepts.com/sem-glove/.

[22] PARO Robots, U.S. I. PARO Therapeutic Robot [Internet]. 2014. Available from: http://www.parorobots.com/.

[23] Leka [Internet]. [cited 2019 Jan 3]. Available from: https://leka.io/.

[24] Cutii [Internet]. [cited 2019 Jan 3]. Available from: https://www.cutii.io/en/.

[25] ZIPLINE. Zipline - Service - Zipline provides a seamless delivery service, rain or shine. [Internet]. [cited 2018 May 12]. Available from: http://www.flyzipline.com/service/.

[26] Physio-Control Inc. Welcome to Lucas CPR • LUCAS CPR • LUCAS ${ }^{\mathrm{TM}}$ CPR [Internet]. [cited 2018 May 12]. Available from: http://www.lucas-cpr.com/.

[27] Social care user surveys - NHS Digital [Internet]. [cited 2018 Apr 9]. Available from: https://digital.nhs.uk/social-care-user-surveys.

[28] Shaw TC, Bunch J, Carlson L. 2015 - 2016 COMMUNITY HEALTH NEEDS ASSESSMENT [Internet]. 2015 [cited 2018 Apr 9]. Available from: https://www.usahealthsystem.com/workfiles/usacwh_docs/2015-16-USA-CHNA.pdf.

[29] WA Primary Health Network. Needs Assessment Reporting Template Summary 
[Internet]. Radcliffe Medical Press; 2016 [cited 2018 Apr 9]. Available from: http://www.wapha.org.au/wp-content/uploads/2016/08/160812_Public-Facing-PHNNeeds-Assessment-Reporting-template_Country-PHN_final-web-v-1.1.pdf.

[30] Atkinson AB, Marlier E. Income and living conditions in Europe [Internet]. EUROSTAT Stat. Books. 2010 [cited 2018 Apr 9]. Available from: http://ec.europa.eu/eurostat/documents/3217494/5722557/KS-31-10-555-EN.PDF.

[31] Huskens B, Palmen A, Van der Werff M, et al. Improving Collaborative Play Between Children with Autism Spectrum Disorders and Their Siblings: The Effectiveness of a Robot-Mediated Intervention Based on Lego ${ }^{\circledR}$ Therapy. J. Autism Dev. Disord. [Internet]. 2015 [cited 2019 Jan 2];45:3746-3755. Available from: http://www.ncbi.nlm.nih.gov/pubmed/25428293.

[32] Pino M, Boulay M, Jouen F, et al. “Are we ready for robots that care for us?” Attitudes and opinions of older adults toward socially assistive robots. Front. Aging Neurosci. [Internet]. 2015 [cited 2018 Mar 19];7:141. Available from: http://journal.frontiersin.org/Article/10.3389/fnagi.2015.00141/abstract.

[33] Huijnen CAGJ, Lexis MAS, Jansens R, et al. How to Implement Robots in Interventions for Children with Autism? A Co-creation Study Involving People with Autism, Parents and Professionals. J. Autism Dev. Disord. [Internet]. 2017 [cited 2019 Jan 2];47:3079-3096. Available from: http://link.springer.com/10.1007/s10803-017$3235-9$.

[34] Zubrycki I, Granosik G. Understanding Therapists' Needs and Attitudes Towards Robotic Support. The Roboterapia Project. Int. J. Soc. Robot. [Internet]. 2016 [cited 2019 Jan 2];8:553-563. Available from: http://link.springer.com/10.1007/s12369-016$0372-9$.

[35] Michaud F, Boissy P, Labonte D, et al. Telepresence robot for home care assistance. AAAI Spring Symp. - Tech. Rep. [Internet]. 2007 [cited 2018 Mar 19];SS-07-07:5055. Available from: http://www.aaai.org/Papers/Symposia/Spring/2007/SS-0707/SS07-07-012.pdf.

[36] Martin-Ortiz M, Kim MG, Barakova EI. Mobile application for executing therapies with robots. Lect. Notes Comput. Sci. (including Subser. Lect. Notes Artif. Intell. Lect. Notes Bioinformatics) [Internet]. Springer, Cham; 2017 [cited 2019 Jan 2]. p. 82-92. Available from: http://link.springer.com/10.1007/978-3-319-59147-6_8.

[37] Feil-Seifer D, Skinner K, Matarić MJ. Benchmarks for evaluating socially assistive robotics. Interact. Stud. [Internet]. 2007 [cited 2019 Jan 2];8:423-439. Available from: https://robotics.usc.edu/publications/media/uploads/pubs/537.pdf.

[38] Eurostat. GDP at regional level Statistics Explained [Internet]. Eurostat. 2018 [cited 2019 Jan 2]. Available from: https://ec.europa.eu/eurostat/statisticsexplained/index.php/GDP_at_regional_level\#Regional_gross_domestic_product_.28G DP.29_per_inhabitant.

[39] Office for National Statistics. Population Estimates for UK, England and Wales, Scotland and Northern Ireland, Population Density Tables, 1981 to 2010 [Internet]. ONS. 2012 [cited 2017 Oct 21]. p. 1-23. Available from: https://www.ons.gov.uk/peoplepopulationandcommunity/populationandmigration/pop ulationestimates/bulletins/annualmidyearpopulationestimates/mid2016. 
[40] Institute of Public Care. Care Sector Business and Skills Analysis [Internet]. 2015 [cited 2017 Oct 25]. Available from: https://ipc.brookes.ac.uk/publications/Cornwall_Report_Final.pdf.

[41] Ron Davies. Older people in Europe - EU Policies and Programmes. 2014 [cited 2017 Oct 25];8. Available from: http://www.eprs.ep.parl.union.eu.

[42] Local Administrative Units, Directorate General Regional Policy. Degree of urbanisation classification - 2011 revision [Internet]. 2016 [cited 2017 Oct 21]. Available from: http://ec.europa.eu/eurostat/statisticsexplained/index.php/Degree_of_urbanisation_classification_-_2011_revision.

[43] EPIC. Ehealth Productivity and Innovation in Cornwall and the Isles of Scilly (EPIC) University of Plymouth [Internet]. [cited 2018 Jun 5]. Available from: https://www.plymouth.ac.uk/research/epic.

[44] Shibata T, Wada K. Robot therapy: A new approach for mental healthcare of the elderly - A mini-review [Internet]. Gerontology. Karger Publishers; 2011 [cited 2018 Mar 19]. p. 378-386. Available from: http://www.ncbi.nlm.nih.gov/pubmed/20639620.

[45] Moyle W, Cooke M, Beattie E, et al. Exploring the Effect of Companion Robots on Emotional Expression in Older Adults with Dementia: A Pilot Randomized Controlled Trial. J. Gerontol. Nurs. [Internet]. 2013 [cited 2018 May 13];39:46-53. Available from: http://www.healio.com/doiresolver?doi=10.3928/00989134-20130313-03.

[46] Nunez E, Matsuda S, Hirokawa M, et al. Humanoid robot assisted training for facial expressions recognition based on affective feedback. Lect. Notes Comput. Sci. (including Subser. Lect. Notes Artif. Intell. Lect. Notes Bioinformatics) [Internet]. Springer, Cham; 2015 [cited 2018 Mar 19]. p. 492-501. Available from: http://link.springer.com/10.1007/978-3-319-25554-5_49.

[47] Jung MM, van der Leij L, Kelders SM. An Exploration of the Benefits of an Animallike Robot Companion with More Advanced Touch Interaction Capabilities for Dementia Care. Front. ICT. 2017;4:1-11.

[48] Wong LP. Focus group discussion: a tool for health and medical research. Singapore Med. J. [Internet]. 2008 [cited 2018 Mar 17];49:256-260; quiz 261. Available from: https://umexpert.um.edu.my/file/publication/00007704_17969.pdf.

[49] Thomas DR. A General Inductive Approach for Analyzing Qualitative Evaluation Data. Am. J. Eval. [Internet]. 2006 [cited 2018 Oct 13];27:237-246. Available from: http://journals.sagepub.com/doi/10.1177/1098214005283748.

[50] Welsh E. Dealing with data: Using NVivo in the qualitative data analysis process. Forum Qual. Soc. Res. [Internet]. 2002 [cited 2018 Apr 25];3:Art 26. Available from: http://www.qualitativeresearch.net/index.php/fqs/article/view/865/1880\&q=nvivo+manual\&sa=x\&ei=zah_t5 pqoyubhqfe9swgbq\&ved=0cc4qfjaj.

[51] Intille SS. Designing a home of the future [Internet]. IEEE Pervasive Comput. 2002 [cited 2019 Jan 4]. p. 76-82. Available from: http://computer.org/pervasive.

[52] Piezzo C, Suzuki K. Feasibility study of a socially assistive humanoid robot for Guiding elderly individuals during walking. Futur. Internet [Internet]. 2017 [cited 
2018 Mar 19];9:30. Available from: http://www.mdpi.com/1999-5903/9/3/30.

[53] Yusif S, Soar J, Hafeez-Baig A. Older people, assistive technologies, and the barriers to adoption: A systematic review [Internet]. Int. J. Med. Inform. Elsevier; 2016 [cited 2018 Jul 23]. p. 112-116. Available from:

https://www.sciencedirect.com/science/article/pii/S1386505616301551.

[54] Wolbring G, Yumakulov S. Social Robots: Views of Staff of a Disability Service Organization. Int. J. Soc. Robot. [Internet]. 2014 [cited 2019 Jan 4];6:457-468. Available from: http://link.springer.com/10.1007/s12369-014-0229-z.

[55] Sparrow R, Sparrow L. In the hands of machines? the future of aged care. Minds Mach. [Internet]. 2006 [cited 2019 Jan 4];16:141-161. Available from: http://link.springer.com/10.1007/s11023-006-9030-6.

[56] Coeckelbergh M, Pop C, Simut R, et al. A Survey of Expectations About the Role of Robots in Robot-Assisted Therapy for Children with ASD: Ethical Acceptability, Trust, Sociability, Appearance, and Attachment. Sci. Eng. Ethics [Internet]. 2016 [cited 2017 Oct 30];22:47-65. Available from: http://tethys.eaprs.cse.dmu.ac.uk/rri/sites/default/files/obs-concept-impactsvalues/art\%253A10.1007\%252Fs11948-015-9649-x.pdf.

[57] Nomura T, Kanda T, Suzuki T. Experimental investigation into influence of negative attitudes toward robots on human-robot interaction. AI Soc. [Internet]. 2006 [cited 2019 Jan 8];20:138-150. Available from: http://link.springer.com/10.1007/s00146005-0012-7.

[58] van Wynsberghe A. Designing Robots for Care: Care Centered Value-Sensitive Design. Sci. Eng. Ethics [Internet]. 2013 [cited 2018 Apr 9];19:407-433. Available from: http://link.springer.com/10.1007/s11948-011-9343-6.

[59] Sharkey A, Sharkey N. Granny and the robots: Ethical issues in robot care for the elderly. Ethics Inf. Technol. [Internet]. 2012 [cited 2019 Jan 4];14:27-40. Available from: https://philpapers.org/archive/SHAGAT.pdf.

[60] Kennedy J, Lemaignan S, Montassier C, et al. Child Speech Recognition in HumanRobot Interaction. Proc. 2017 ACM/IEEE Int. Conf. Human-Robot Interact. - HRI '17 [Internet]. 2017 [cited 2019 Jan 8]. p. 82-90. Available from: http://dx.doi.org/10.1145/2909824.3020229.

[61] Vilchis A, Troccaz J, Cinquin P, et al. A New Robot Architecture for TeleEchography. IEEE Trans. Robot. Autom. [Internet]. 2003 [cited 2019 Jan 4];19:922926. Available from: http://citeseerx.ist.psu.edu/viewdoc/download?doi=10.1.1.542.7846\&rep=rep1\&type= pdf.

[62] Tsui KM, Desai M, Yanco HA, et al. Exploring use cases for telepresence robots. Proc. 6th Int. Conf. Human-robot Interact. - HRI '11. New York, New York, USA ACM Press; 2011. p. 11

[63] Stanberry B. Telemedicine: Barriers and opportunities in the 21st century [Internet]. J. Intern. Med. 2000 [cited 2019 Jan 8]. p. 615-628. Available from: https://onlinelibrary.wiley.com/doi/pdf/10.1046/j.1365-2796.2000.00699.x.

[64] Lin CA, Shah K, Mauntel LCC, et al. Drone delivery of Medications: Review of the 
landscape and legal considerations [Internet]. Am. J. Heal. Pharm. American Society of Health-System Pharmacists; 2018 [cited 2019 Jan 9]. p. 153-158. Available from: http://www.ncbi.nlm.nih.gov/pubmed/29237587.

[65] Swangnetr M, Zhu B, Taylor KB, et al. Assessing the Effects of Humanoid Robot Features on Patient Emotion during a Medicine Delivery Task [Internet]. Proc. Hum. Factors Ergon. Soc. Annu. Meet. SAGE PublicationsSage CA: Los Angeles, CA; 2010 [cited 2019 Jan 8]. p. 349-353. Available from: http://journals.sagepub.com/doi/10.1177/154193121005400417.

[66] Broadbent E, Stafford R, MacDonald B. Acceptance of healthcare robots for the older population: Review and future directions [Internet]. Int. J. Soc. Robot. 2009 [cited 2018 Apr 9]. p. 319-330. Available from:

https://s3.amazonaws.com/academia.edu.documents/45751247/s12369-009-0030620160518-24489.

1rd1itt.pdf?AWSAccessKeyId=AKIAIWOWYYGZ2Y53UL3A\&Expires=152329222 $8 \&$ Signature $=4 \% 2 \mathrm{BccW} 5 \mathrm{UwqmCLGO6ccE2gs8YSSqA} \% 3 \mathrm{D} \&$ response-contentdisposition=inline $\% 3 \mathrm{~B}$ filename $\% 3 \mathrm{DAccept}$.

[67] European Commission. Population Grids - Statistics Explained. EuroStat pages [Internet]. GeoStat pages. 2016 [cited 2018 Jun 5]. Available from: http://ec.europa.eu/eurostat/statistics-explained/index.php?title=Population_grids. 


\section{Appendix}

\section{EPIC Focus Groups sheet}

\section{EPIC Local Workshop: September 2017}

Use this sheet to list one area where technology might help health or social care. We will collect all sheets but the group should prioritise the top 5 .

- What is the problem or situation that technology might help with?

- Do you have any ideas for the technology? What is the nature of the technology?

\begin{tabular}{|c|c|}
\hline $\begin{array}{l}\text { Who in your } \\
\text { breakout group } \\
\text { has suggested } \\
\text { this topic? Who } \\
\text { seems to be the } \\
\text { main 'owner'? }\end{array}$ & $x^{2}$ \\
\hline $\begin{array}{l}\text { What is the } \\
\text { problem or } \\
\text { situation that } \\
\text { technology } \\
\text { might help } \\
\text { with? }\end{array}$ & \\
\hline $\begin{array}{l}\text { Do you have any } \\
\text { ideas for the } \\
\text { technology? } \\
\text { What is the } \\
\text { nature of the } \\
\text { technology? }\end{array}$ & \\
\hline $\begin{array}{l}\text { How do you } \\
\text { want it to help? }\end{array}$ & \\
\hline
\end{tabular}

